\title{
A Case Of Bilateral Acquired Localized Lipoatrophy
}

\author{
Osman Tanrıkulu ${ }^{a}$ Yavuz Yesilova $^{\mathrm{b}}$ Mustafa Aksoy $^{\mathrm{a}}$ \\ ${ }^{a}$ Department of Dermatology, Harran University School of Medicine, Şanlıurfa, Turkey; \\ ${ }^{\mathrm{b}}$ Dermatology Clinic, Health Sciences University, Training and Research Hospital, \\ Van, Turkey
}

\section{Keywords}

Lipoatrophy · Lipodystrophy · Steroid injection

\begin{abstract}
Lipoatrophy is characterized by inflammation and tissue loss in fatty tissue. This disease may be congenital or acquired, primary or secondary. Secondary lipoatrophy develops with infections, collagen tissue diseases, tumors and drug injections. In this report, we present the case of a 14-year-old female patient who developed lipoatrophy following intramuscular steroid injection to both buttocks.

(C) 2016 The Author(s)

Published by S. Karger AG, Basel
\end{abstract}

\section{Case Presentation}

A 14-year-old female patient presented to our clinic with the symptom of hollowness that had been present in both gluteal areas for 6 months. The patient, who did not have any history of topical medication, redness, pain or itching in the hollowed area and did not describe any signs, had been receiving corticosteroid injections due to urticaria for the last 6 months. The patient did not have any particularities in her personal history, and there were no persons in her family with similar symptoms.

The patient's dermatological physical examination revealed an atrophic, oval and plaque-like lesion symmetrically localized on both thighs with a diameter of approximately $3 \times 4 \mathrm{~cm}$ linearly overlaid by two flesh-colored striae with a diameter of approximately $1 \times 4$ 
$\mathrm{cm}$. The system examination result was normal (fig. 1, fig. 2). The patient's laboratory values were normal, and the deep incisional biopsy collected from the patient was found to be consistent with acquired localized lipoatrophy (ALL). Histopathological examination revealed partly necrotic-looking adipocytes embedded among fibrous septa in the subcutaneous tissue interspersed with a few inflammatory cells. Normal fat tissue was not observed (fig. 3). The patient was diagnosed with ALL in light of the clinical and histopathological information. The patient did not accept any treatment options, surgical or other. The option of spontaneous healing was taken into account, and control visits at the Dermatology outpatient clinic once every 3 months were recommended for our patient.

\section{Discussion}

Lipoatrophy is characterized by a preceding inflammatory period and consequent fat loss in the subcutaneous tissue. As for lipodystrophy, it refers to the absence of subcutaneous fat tissue without any signs of inflammation. Lipoatrophy may be congenital or acquired and localized or diffused depending on the area of involvement. ALL appears in primary (idiopathic) or secondary forms. Primary and idiopathic lipoatrophy has clinical forms such as lipoatrophia semicircularis, lipodystrophia centrifugalis abdominalis infantilis and involutional lipoatrophy. Secondary lipoatrophy develops due to reasons such as pyogenic abscesses, connective tissue diseases (lupus erythematosus, morphea, dermatomyositis or overlap disease), neoplasm (T-cell lymphoma) and iatrogenic (subcutaneous, intramuscular and dermal injections) factors [1].

ALL frequently develops secondary to dermal or intramuscular drug injections of corticosteroids as seen with our case. Additionally, ALL has also been reported following insulin, vasopressin, recombinant growth hormone, adrenal cortex hormone and methotrexate injections [2-4].

Lipoatrophy that develops due to subcutaneous corticosteroid injection results in two different histopathological pictures. In the first histopathological picture, there are small, retracted, slightly acidophilic or albuminous fat tissues surrounding the septal connective tissue accompanied by sparse inflammatory cells and prominent blood vessels. In the second histopathological picture, there are small, atrophic fat tissues around vascular structures. Decreased adipocyte counts and small-sized lobules are identified in all patients. The histopathological picture in our case is more consistent with the first group [1].

ALL diagnosis is based on the basis of clinical signs, physical examination, including deep incisional biopsy, and anamnesis. Primary localized lipoatrophy is generally selflimiting and may not require treatment. If the clinical signs persist and the patient has cosmetic concerns, liposuction and localized fat transplantation can be performed in a combined fashion [1].

\section{Statement of Ethics}

The authors have no ethical conflicts to disclose. 


\section{Case Reports in

\section{Disclosure Statement}

The authors declare no conflicts of interest.

\section{References}

-1 Avilés-Izquierdo JA, Longo-Imedio MI, Hernánz-Hermosa JM, Lázaro-Ochaita P: Bilateral localized lipoatrophy secondary to a single intramuscular corticosteroid injection. Dermatol Online J 2006;12:17 Buyukgebiz A, Aydin A, Dundar B, Yorukoglu K: Localized lipoatrophy due to recombinant growth hormone therapy in a child with 6.7 kilobase gene deletion isolated growth hormone deficiency. J Pediatr Endocrinol Metab 1999;12:95-97.

-3 Hamidou M, Barrier JH, Planchon B, Raffi F, Grolleau JY: Lipoatrophy of the buttocks after intramuscular injection of adrenal cortex hormones (in French). Rev Med Interne 1991;12:316.

- Haas N, Henz BM, Bunikowski R, Keitzer R: Semicircular lipoatrophy in a child with systemic lupus erythematosus after subcutaneous injections with methotrexate. Pediatr Dermatol 2002;19:432-435.

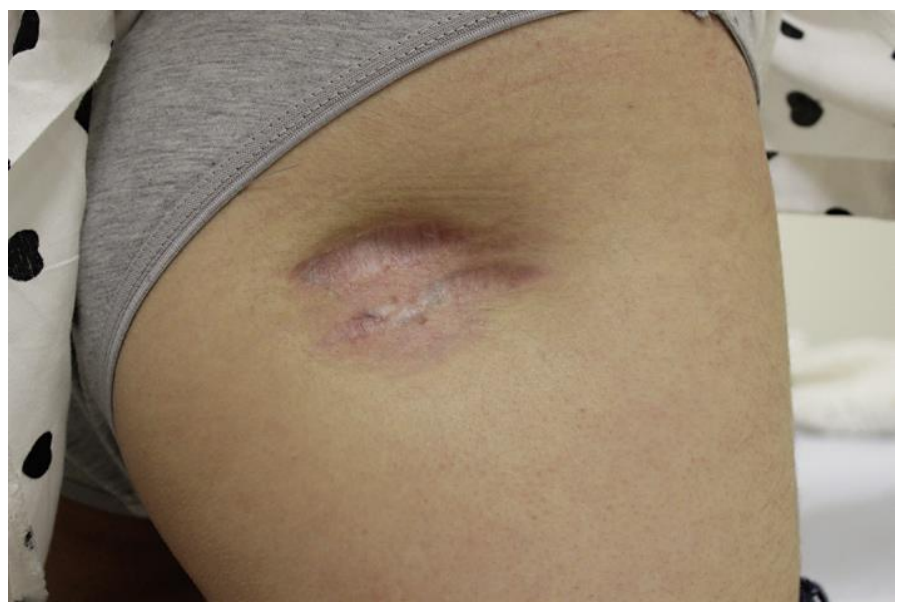

Fig. 1. An atrophic, oval and plaque-like lesion symmetrically localized on the right thigh. 


\section{Case Reports in

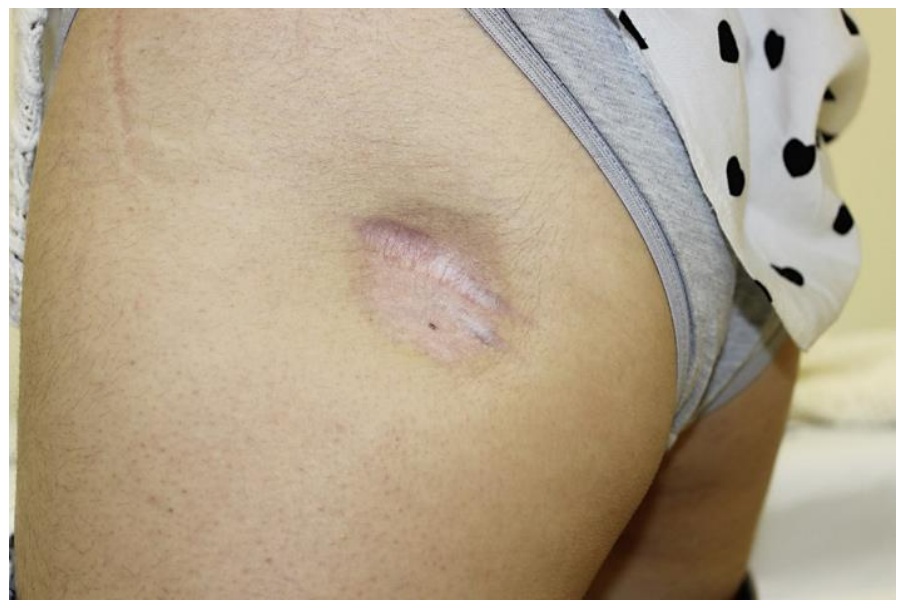

Fig. 2. An atrophic, oval and plaque-like lesion symmetrically localized on the left thigh.

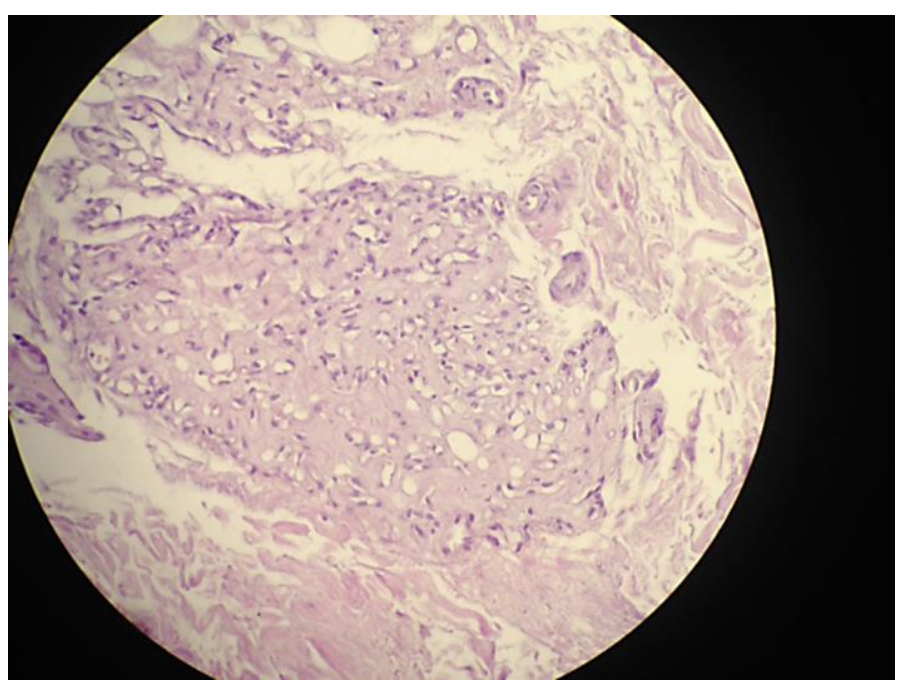

Fig. 3. Partly necrotic-looking adipocytes are embedded among fibrous septa in the subcutaneous tissue interspersed with a few inflammatory cells. Normal fat tissue was not observed. 